\title{
Heterotaxy Syndrome with Asplenia
}

National Cancer Institute

\section{Source}

National Cancer Institute. Heterotaxy Syndrome with Asplenia. NCI Thesaurus. Code C101326.

A congenital defect in which there is an abnormal spatial arrangement of the internal thoraco-abdominal organs; in this manifestation of the disorder, the spleen is absent. 